\title{
Design, adoption and implementation of electronic waste policies in India
}

\author{
Anwesha Borthakur ${ }^{1}$ (D)
}

Received: 12 August 2021 / Accepted: 20 January 2022 / Published online: 9 February 2022

(c) The Author(s), under exclusive licence to Springer-Verlag GmbH Germany, part of Springer Nature 2022

\begin{abstract}
Globally, E-waste is experiencing an unprecedented growth in the recent years. This growth will be fueled further by the COVID-19 pandemic owing to the new work culture where people are becoming more dependent on their electronic products than ever before. However, governance of E-waste, particularly in the Global South, has been a complex phenomenon. Considering this, the current study attempted to assess the design, adoption, and implementation of E-waste policies in India-a major electronics manufacturing hub with a massive consumer electronics market. Taking hints from theoretical concepts such as policy transfer, policy convergence, and policy effectiveness, the study addressed the primary research question: why India adopts E-waste policy approaches that seem inadequate and ineffective in its local contexts and attempts to identify alternative approaches. Through expert interviews and policy document analysis, it was observed that E-waste policy approaches in India are largely influenced by the European Union's Waste Electrical and Electronic Equipment (WEEE) Directive. All the experts interviewed recognized absence of the informal sector in India's policy efforts of both 2011 and 2016 as a significant lacuna in the country's E-waste policy responses. In this paper, the author argues that there should be policy change towards a healthy collaboration between the informal and formal sector where best-of-the-two-worlds could be wisely used for sustainable E-waste governance in India.
\end{abstract}

Keywords E-waste $\cdot$ Formal recycling sector $\cdot$ India $\cdot$ Informal sector $\cdot$ Policy effectiveness $\cdot$ Policy transfer $\cdot$ WEEE Directive

\section{Introduction}

According to the United Nation's Global E-waste Monitor 2020, the world generated an unprecedented 53.6 million metric tonnes (Mt) of E-waste in 2019, a $21 \%$ increase in a mere 5 years' time (Forti et al. 2020). The same report estimated that with $24.9 \mathrm{Mt}$, Asia is the largest generator of E-waste in 2019 and two Asian economies (India and China) along with the USA contributed to $38 \%$ of E-waste generated in the year. At present, the Global South is at the core of electronics manufacturing activities, fulfilling not only the demands of their own populace but also the increasing needs of the Global North. The natural resource- and

Responsible Editor: Philippe Garrigues

Anwesha Borthakur

anwesha227@gmail.com

1 Katholieke Universiteit Leuven (KU Leuven), Parkstraat 45, 3000 Leuven, Belgium energy-exhaustive electronics industry results in an increasing post-consumer waste generation in the form of electronic waste (E-waste). As per a written statement presented at the lower house of Indian parliament (Lok Sabha) on September 23, 2020 by the Union Minister of State in the Ministry of Environment, Forest and Climate Change (MoEF\&CC), India observed a $43 \%$ increase in E-waste generation in a mere 3 years span. ${ }^{1}$ Thus, E-waste has established itself as a major toxic waste stream in India-an emerging economy and the second most populous country in the world (Borthakur and Singh 2020). The existing statistics on E-waste in India is alarming which necessitates stringent policy interventions. With the current COVID-19 pandemic and the evolving new work culture, publics' reliance on electronic equipments has been increasing further and the countries must prepare themselves to deal with an even larger volume of E-waste in the coming years. Although a recently released report by the United Nations University in

\footnotetext{
${ }^{1}$ See https://www.downtoearth.org.in/news/agriculture/as-told-toparliament-september-23-2020-e-waste-up-43-in-3-years-73512.
} 
Bonn documented a decline in E-waste generation during the first three quarters of 2020, the scientists involved in that research have noted it likely to be temporary. ${ }^{2}$

As a rapidly growing waste stream, E-waste threatens to emerge as a global problem of incontrollable magnitude (Zeng et al. 2018). Nevertheless, the Global South is disproportionately challenged by this increasing E-waste volume owing to several factors specific to those regions. For instance, developing countries are subjected to complex challenges associated with inadequate infrastructure, scarcities of human and financial resources, the increasingly complexities of waste, and political hindrances, ranging from institutional failures to petty corruptions (Pereira et al. 2020). In India, diverse economic, infrastructural, socio-cultural, environmental, technological, and political contemplations among its citizen groups pose major challenges in devising a single, commonly accepted and unambiguous E-waste management plan (Borthakur and Govind 2017). Policy and planning must echo routes for creating and delivering a steady socio-economic condition and contribute to facilitate a comprehensive and sustainable development (Asibey et al. 2020). Policy design and implementation represent a major segment of the strategic structure in a country's addressing of domestic issues and ensure an organized approach towards tackling the concern uniformly and legally all over the country (Patil and Ramakrishna, 2020). E-waste policies in India are yet to achieve its desired potentials in terms of tackling this ever-increasing waste crisis. Sustainable management of E-waste is still far from reality, and thus, it is essential to understand the design and development of the current policies.

Understanding E-waste policy developments in emerging economies is a complex phenomenon. Also, the intricacies associated with sustainable E-waste management and policy initiatives could not be studied from a single disciplinary approach and thus call for an interdisciplinary research method. Taking hints from policy-relevant literatures of political sciences, environmental science, and science and technology studies (STS), this study seeks to answer the questions: whether India's E-waste policy an outcome of policy transfer efforts (formal or informal) from the Global North? If so, how effective its adoption and implementation has been? What have been the major gaps in design, adoption, and implementation? Accordingly, an analytical framework has been developed to comprehend the formulation of E-waste policies in India. The developed framework is informed by academic literature on policy transfer, policy convergence, policy effectiveness, and policy change.

\footnotetext{
${ }^{2}$ See https://unu.edu/media-relations/releases/the-impact-of-thecovid-19-pandemic-on-e-waste.html.
}

In both developing and developed countries, public establishments do not necessarily own the requisite expertise to address the complications they confront and regularly look external to their organization, particularly to non-governmental or government organizations for possible responses to their problems (Evans 2017). The authors Dolowitz and Marsh (2000:5) argue that policy transfer along with policy convergence, lesson-drawing, and policy diffusion signifies a process where "the knowledge about policies, administrative arrangements, institutions and ideas in one political setting (past or present) is used in the development of policies, administrative arrangements, institutions and ideas in another political setting." Benson and Jordan (2011) identify four key entities in a policy transfer process: transfer object, actors, mechanism of transfer, and outcome. Policy transfer may lead to "policy convergence," which is a process wherein policies in two or more countries become increasingly alike over the years (Knill 2005). The notion of policy effectiveness resonates a fundamental tenet of the present-day policy sciences: problem-solving (Mukherjee and Bali 2019). In general, policy effectiveness could be well-defined as the degree to which the policies are accomplishing the benefits they are expected to realize in addition to any unforeseen allied advantages (Nagel 1986). Depending on the evaluation of effectiveness of a particular policy, the possible next step forward is a "policy change." Policy change primarily denotes incremental changes in prevailing structures, or novel and innovative policies (Bennett and Howlett 1992). Policy change may lead to a "policy reform" signifying a major change in existing policies. In this paper, the author will analyze the formulation and subsequent implementation of India's E-waste policies through the lens of policy transfer, its convergence, subsequent effectiveness, and whether a policy change is essential or already had taken place.

Current policy approaches on E-waste are largely based on assumptions derived from Western policies, polities, and societies. This makes implementation of those policies in the geo-political set up of the Global South both complicated and tedious. In this paper, I will analyze why emerging economies in general and India in particular adopt $\mathrm{E}$-waste policies that seem inadequate and ineffective in their local contexts and attempt to identify alternative approaches. Emerging economies are characterized by their expanding market potentials plus increasing labor forces and countries falling under the purview of emerging economies are expected to endure growths rather fast in the coming years. ${ }^{3}$ An example of this is the growth of the middle class population in the BRIC (Brazil, Russia, India, and China) who drive major consumer markets in these countries including consumer electronics. India and

\footnotetext{
${ }_{3}$ See https://knowledge4policy.ec.europa.eu/foresight/topic/growingconsumerism/developing-countries-emerging-markets_en.
} 
Table 1 Guiding questions for the semi-structured expert interviews

1. Design of the E-waste policy

- What was the primary reference point or motivation for designing India's E-waste policies of 2011 and 2016 ?

- Do you think India's E-waste policies took inspiration from policies of any other country?

2. Adoption and implementation of the E-waste policy

- What are the challenges in adoption of the E-waste policy in India?

- According to you, is the extended producers' responsibility (EPR) system functioning satisfactorily in the country?

- How do you see the informal sector in the light of the E-waste policy in India?

- According to you, how the collection targets were fixed or set in the E-waste Rules of 2016 which eventually had to be lowered in 2018 ?

China are among the major generators of E-waste in the world today and it is essential to understand their E-waste policy responses. Here, in this paper, I will seek to explain the design, adoption, and implementation of E-waste policies in India and the degree of effectiveness of the policy approaches. It is noteworthy to mention here that India implemented primarily two E-waste policies: (1) E-waste (Management and Handling) Rules 2011 and (2) E-waste (Management) Rules 2016. The E-waste (Management) Rules 2016 was further amended in 2018 with a revised title as "E-Waste (Management) Amendment Rules, 2018." In this study, I focus on the devising and implementation of these rules and identify the subsequent challenges. The major gaps in India's E-waste policymaking have been identified. A description of the methods applied for conducting this study is provided in the "Materials and methods" section. "Results and discussion" section and its subsequent sub-sections discuss the key findings of the study while "Conclusion" section concludes the study and provides future course of possible research actions.

\section{Materials and methods}

The study is essentially qualitative. I started with an in-depth literature search in two major databases: Scopus and Web of Science. A few structured keyword searches were carried out in these two databases towards locating relevant publications. Once academic publications were shortlisted, I looked for related newspaper/periodical articles and policy documents. Overall, nineteen academic publications, India's two E-waste rules and articles particularly published in the country's foremost environmental magazine "Down to Earth" were found to be relevant for this paper. Policy document analysis and expert interviews constitute the core methods of this study. It is noteworthy that E-waste policy or governance studies in India are still few and far between. Accordingly, I decided to get in touch with some experts on the topic with possible interview request. Again, considering the limited research and policy attention on the topic in India, individuals having expert opinion on the topic are often limited. Nevertheless, I managed to interview four experts with knowledge on E-waste policymaking in the country. One central government official, one expert from a national NGO, and two academics working at two renowned institutes in India were interviewed for the study purpose. The data from policy document analysis and expert interviews was used to trace the process of E-waste policy inception, design, and implementation in order to find answers to the integral parts of the research question: (a) to what extent are India's E-waste policies and management practices (in) effective? and (b) why is this the case?

A semi-structured questionnaire was devised for the expert interviews. The interviews were carried out in two sets: first in April 2019 followed by October to December 2019. Often in policy research, semi-structured interviews are used where, although a guideline is considered with the must-covered topics/questions, the interviewer possesses certain degree of discretion regarding the order of the questions to be asked in a somewhat conversational style (Harrell and Bradley 2009). The objective of the semi-structured interviews is to explore a topic intensely and to comprehend meticulously the answers provided by the interviewee. In a novel topic like E-waste governance in India, semi-structured expert interviews provide the requisite flexibility to the interviewer to delve deeply into a conversation in search of possible relevant responses. The interviewees were provided with an "Informed Consent Form." Thus, prior consent was undertaken for conducting the interviews. The data from the interviews has been pseudonymized adhering to the privacy protocols.

The guiding questions for the expert interviews were divided fundamentally into two parts: (1) design of the E-waste policy and (2) adoption and implementation of the E-waste policy (Table 1).

\section{Results and discussion}

At the outset, the author in this study attempted to identify the specifics of the four key entities in the policy transfer process as suggested by Benson and Jordan (2011) in the context of India's E-waste Rules of 2011 and 2016: 
I Transfer object: E-waste policy (informal transfer)

All the four experts (E01, E02, E03, and E04) suggested that E-waste policy approaches in India are largely influenced by the European Union's (EU) Waste Electrical and Electronic Equipment (WEEE) Directive which entered into force in 2003. The EU has been a forerunner in advocating sustainable E-waste management practices through its legislations which, in turn, have been important reference points for many countries worldwide (Borthakur and Singh 2020). One of the experts (E01) stated that the initiatives towards devising a proposed E-waste management policy started during 2003-2004. Another expert (E02) opined that India looked for a reference while preparing the first draft of the E-waste rules. There was hardly any reference in the horizon. Most visible and already experimented evidence was EU's WEEE Directive. According to the same expert (E02), although there was no "formal" policy transfer, India's E-waste policies drew considerable references from the EU's Directive particularly with respect to the concepts pertaining to the legal framework. Thus, the EU's Directive acted as the primary reference point while devising India's E-waste policy responses.

\section{Actors}

From the existing literature, following actors are identified who are instrumental in any E-waste policy transfer interventions including India's:

- Government authorities

- Think tanks, policy institutes, NGOs

- Producer responsibility organizations (PRO)

- Academicians/researchers working on E-waste

\section{Mechanism of transfer: voluntary}

As mentioned in the previous section by an expert (E02), there was no "formal" policy transfer effort from the EU with respect to its WEEE Directive while formulating India's E-waste policies. In absence of a formal policy transfer, it could be postulated that the transfer mechanism was largely "voluntary." Expert (E01) argued that India's both recent E-waste rules (of 2011 and 2016) attempted to merge the key characteristics of the EU's WEEE Directive and Restriction of Hazardous Substances (RoHS) Directive, another landmark policy document from the continent. He considered the E-waste (Management and Handling Rules) 2011 as a kind of "tutorial" in India's policymaking effort while deeming the E-waste (Management) Rules 2016 as a more concrete policy intervention.

IV. Outcome: imitation and inspiration
The E-waste policymaking process in India has the potential to be a result of a "rational imitation" where government officials (along with its partner stakeholders) consider a few efficacious policies towards formulating their own policy responses. Experts (E01, E02, and E04) believed that India's E-waste policies are inspired by the EU's WEEE Directive. The fact that EPR is at the core of policy approaches of both EU and India signals to such inspiration. As E-waste governance in India is largely influenced by the local socioeconomic, cultural, environmental health circumstances of the country, it is subjected to major challenges in the implementation phase.

The following sections discuss the major attributions (and inadequacies) of E-waste policy approaches in India with particular emphasis on the design, adoption, and implementation processes. The sections address the most unique and notable concerns associated with Indian E-waste rules as compared to its EU counterparts in the form of WEEE and RoHS Directives. Such a detailed account on Indian policies will help conclude the study in terms of policy transfer, policy convergence, policy effectiveness, and policy change efforts.

\section{Absence of the informal sector in E-waste policies}

One of the most striking observations on both the E-waste (Management) Rules 2016 and E-waste (Management and Handling Rules) 2011 is the absence of addressal of the informal recycling sector. All the experts interviewed for this study acknowledged this concern as a significant lacuna in India's E-waste policy processes. In numerous developing countries, E-waste recycling is mostly operated by the informal sector through its involvement in processes ranging from collection, reuse, recycling, refurbishment up to the final disposal of residues (Ackah 2017). India is no exception. Overall, the management of recyclable waste such as papers, plastics, metals, and glasses is dominated by the informal waste recycling sector in India. E-waste is relatively a recent addition to the recyclable waste having potential to incur financial returns. A range of economic, political, spatial, and socio-cultural factors largely determines the advent and development of the informal E-waste activities (Asibey et al. 2020). For instance, the rural-to-urban migration where a large number of low-skilled workers move cityward in search of employment opportunities fulfills the labor demand in the informal E-waste recycling sector in India. However, as observed in the well-known informal recycling site Agbogbloshie-Accra in Ghana, the governance and organization of this sector is characterized by the tenacious struggles over power and interest resulting in the generation of disrespect, inequality, misrecognition, incorrect allegations, devaluation, neglect, abuse of rights/freedom, and overall exclusion (Amuzu 2018). 
India is no exception to the global characteristic of waste work being stigmatized where the marginalized section of the society, Dalits and Adivasis, disproportionately constitute the waste workers in the country, and thus, the sector cannot be viewed as caste-neutral (Harriss-White and Rodrigo 2016). In their book "Waste of a Nation: Garbage and Growth in India," Doron and Jeffrey (2018) argue that waste workers are stigmatized and injured as they handle decaying garbage, toxic chemicals, and sewage. They further state that the critical component of the country's association with waste would be the "empathy for marginalized underclasses" who almost invisibly survive amidst waste generated largely for the comfort of the affluent class. While waste in India is converting into a foremost developmental challenge, it will be essential for the future waste policies to traverse the divided informal waste economies along with the urban political universe and its informalized and disjointed bureaucratic procedures (Harriss-White 2020).

In India, scrap dealers or "Kawadiwalas" pick up recyclable waste from individual households or bulk consumers through a system of door-to-door collection and direct the collected waste to the recyclers (Borthakur and Govind 2017). They operate through an excellent network in major Indian cities and towns. With significant environmental and human health impacts, primitive rudimentary recycling practices are regularly used in the developing countries towards material resource retrieval from E-waste (Ackah 2017). Considering the socio-economic, political, and environmental intricacies allied to the informal recycling sector, the absenteeism of this sector in India's E-waste rules is concerning. As argued by Davis (2020: 102), "Without discounting the harmful working conditions and environmental pollution of informal e-waste recyclers that have played a key role in spurring e-waste policies that create formal management systems, recent literature has argued that the historic and future livelihoods of those collecting and processing e-waste along with their experience and expertise have been neglected by these policies." In nonappearance of this sector in the E-waste policies in India, the question remains: how the country deals with the socio-economic, environmental health, and associated concerns of this sector which is instrumental in diverting a massive volume of waste from the landfill and create ample employment opportunities.

As argued by one of the experts (E02), the recent and currently in-practice E-waste (Management) Rules of 2016 ignores the informal sector completely. India's E-waste rules, inspired largely by the EU's WEEE Directive, fail to address the informal sector. The European scenario of waste management is considerably different from that of India. Overall, there is a significant difference between waste management approaches in the Global North and Global South. One of the most notable examples in this context is the dominance of the informal sector in the Global South against a formalized waste management system in the Global North. For instance, although not equally effective and uniform, European Union Member States are at the forefront of E-waste collection in the world through a formalized waste collection and recycling approach. An NGO named Recupel in Belgium alone collected $10.3 \mathrm{~kg}$ of E-waste per inhabitant in 2018 which is more than 117,000 tonnes in total volume. ${ }^{4}$ Along with collaborating with the local municipal corporations for larger collections, the NGO introduced recycling points (the blue boxes) in local supermarkets, electronics shops etc. for better convenience of the consumers and for reaching higher collection targets. Although a few such initiatives have been introduced in India, dominance of the informal sector mostly outpowered them. Therefore, this informal vs. formal recycling sector debate is instrumental in India's policy efforts. For an all-inclusive and potentially successful E-waste governance in India, the informal sector with its inherent characteristics should be adequately addressed. Considering the contribution of this sector in the country's waste management and livelihood generation, success of E-waste policies without satisfactorily addressing this sector is highly unlikely. Therefore, an E-waste policy transfer effort from the Global North will not yield success unless it is restructured to suit the characteristics of the native circumstances and aligned accordingly. A lot of debates and discussions with all stakeholders are essential to situate an effective and workable policy solution in India.

\section{Comprehensiveness of E-waste policies}

How comprehensive India's E-waste policy responses have been? This is a primary concern necessitating attention while devising E-waste governance measures in a country as vast and diverse as India. The insertion of both "individual" and "bulk" consumers in India's E-waste rules is a significant step forward towards an inclusive E-waste management effort. These two sets of consumers together decide the fate of E-waste governance in any country. Nevertheless, concerns arise regarding the electrical and electronic equipments (EEEs) that are currently included under the horizon of India's E-waste rules. It is noteworthy that only twentyone varieties of EEEs fall under the purview of the E-waste (Management) Rules 2016 at present. As argued by one of the experts (E02) during the interview, it is not clear how and why those twenty-one types of EEEs were selected in particular to be added in the rules. The selection criteria are not transparent. Further, another expert (E01) identified that eleven out of the twenty-one products (such as mobile phones and refrigerator) listed in the E-waste (Management) Rules 2016 are primarily utilized by "individual" consumers.

\footnotetext{
${ }^{4}$ See https://www.recupel.be/en/.
} 
As the rules are meant for both "individual" and "bulk" consumers, the comprehensiveness of the policy interventions could expected to be much wider.

Electronic and electrical equipments coming under the purview of the E-waste (Management and Handling) Rules 2011 and the E-waste (Management) Rules 2016 remain almost constant. Only one additional category of equipment in the form of compact fluorescent lamp (CFL) bulb was added in the E-waste (Management) Rules 2016. Experts (E01 and E04) further opined that considering the constantly increasing penetration of different varieties of electronic products into the market every single year, it is not adequate to add just twenty-one categories of products under the horizon of the current rules. In an ideal scenario, new varieties of electrical and electronic products should continuously be included in the rules over the years so that a holistic effort could be undertaken for sustainable E-waste management. An expert (E02) acknowledged that Indian policymakers had limited knowledge and experience while the conversation on devising an E-waste policy began in 2008. Overall, E-waste has been a relatively recent stream of toxic waste then. He further argued that inclusion of only limited electrical and electronic products under the purview of the rules looked rational and convenient. Including a large variety of products at the onset of the policy adoption could have been chaotic. The initial intention was to incorporate those twenty-one varieties in the annex of the E-waste rules and subsequently add more and more EEEs into the list over the time. However, as suggested by him (E02), it is not happening since then because of reasons such as (1) the review process of the E-waste rules is not regular and frequent; (2) there are certain kind of resistance from the electronic industries; and (3) capturing the data on the generation of E-waste is yet to be accomplished.

Although EU's WEEE Directive considerably influenced India's E-waste policymaking initiatives, both Indian E-waste Rules of 2011 and 2016 are far from being as inclusive as the WEEE Directive. Almost all EEEs thinkable are included under the purview of the WEEE Directive. As argued by one of the experts (E04), electronics is not only one of the largest industries in the world, it is also one of the fastest growing industries in terms of innovation and market potential. He emphasized that this industry would continue its remarkable growth in the near future and contribute to an increasing E-waste generation. As the second most populous country, India has one of the largest markets for EEEs in the world. Accordingly, it is the need of the hour to bring more EEEs under the purview of India's E-waste rules (E04).

One of the experts (E02) made yet another interesting observation on comprehensiveness of India's E-waste rules. While he acknowledged that it is not possible to include all the EEEs available in the market in the rules at a single go, policymakers must decide their priorities for EEEs in terms of their "recyclability" or "toxicity." He argued that with circular economy being at the center of most E-waste management efforts, there are much more focus on "recovery" of metals as compared to "toxicity" of metals and other components. In the process, environmental health concerns are taking a backseat and negligible focus has been directed to some highly "toxic" EEEs which should ideally have been a priority for inclusion in the E-waste rules.

Today, electronic and electrical products are being introduced into the market at an unprecedented pace. Consumer markets in the emerging economies are far from saturation and this gives enough space to the newly developed EEEs to flourish and evolve. Consequently, the volume of E-waste generated is also growing extraordinarily in countries like India and China. Therefore, inclusivity and comprehensiveness of E-waste policies in emerging economies determine the overall success of a waste management initiative. It is essential to gradually and systematically bring as many EEEs as possible under the purview of the current E-waste rules in India. This will enable responsible management of this toxic category of waste in the country.

\section{Ambiguities regarding the collection targets}

The Indian Ministry of Environment, Forest and Climate Change (MoEF\&CC) on March 22, 2018, amended the E-Waste (Management) Rules 2016 with a revised title as "E-Waste (Management) Amendment Rules, 2018" (Henam 2018). One of the major features of this amendment was the revision of the E-waste collection targets for the industries. In an unusual step forward, the collection targets were reduced for the initial few years from the previous targets. For instance, the phase-wise targets as per the target-based collection approach introduced in the E-Waste (Management) Rules 2016 are provided in Table 2. However, as illustrated in Table 3, according to the amended rules of 2018, the industries are accountable for collecting only $10 \%$ of E-waste (by weight) during 2017-2018, 20\% during 2018-2019, 30\% during 2019-2020 and so on (MoEF\&CC 2018: 6). As observed by one of the experts (E01), the collection target during the seventh year, i.e., 2023 onward, had been kept the same in both versions of the rules as $70 \%$ of the quantity of waste generation.

According to an expert (E02), this ambiguity in the collection target is a result of no credible data being available on the lifespan of EEEs in India. This made the authorities estimate the lifespan of EEEs available in the Indian market quite arbitrarily. As suggested by him, although E-waste policymaking in India was initiated as a democratic process considering the industry representatives, there remained a gap in information between the policymaking authorities and the industries. The collection targets had to be revised because the earlier targets were too ambitious for the 
Table 2 Collection targets for extended producer responsibility as per E-waste (Management) Rules 2016

\begin{tabular}{lc}
\hline Year & E-waste collection target (number/weight) \\
\hline During first 2 years of implementation of rules & $\begin{array}{c}30 \% \text { of the quantity of waste generation as indicated in Extended Producer Respon- } \\
\text { sibility Plan }\end{array}$ \\
During third and fourth years of implementation of rules & $40 \%$ of the quantity of waste generation as indicated in Extended Producer Respon- \\
& sibility Plan \\
During fifth and sixth years of implementation of rules & $50 \%$ of the quantity of waste generation as indicated in Extended Producer Respon- \\
& sibility Plan \\
Seventh year onward of implementation of rules & $70 \%$ of the quantity of waste generation as indicated in Extended Producer Respon- \\
& sibility Plan
\end{tabular}

MoEF\&CC 2016: 22

Table 3 Revised collection targets for extended producer responsibility as per E-waste (Management) Rules 2018

\begin{tabular}{ll}
\hline Year & E-waste collection target (weight) \\
\hline $2017-2018$ & $10 \%$ of the quantity of waste generation as indicated in Extended Producer Responsibility Plan \\
$2018-2019$ & $20 \%$ of the quantity of waste generation as indicated in Extended Producer Responsibility Plan \\
$2019-2020$ & $30 \%$ of the quantity of waste generation as indicated in Extended Producer Responsibility Plan \\
$2020-2021$ & $40 \%$ of the quantity of waste generation as indicated in Extended Producer Responsibility Plan \\
$2021-2022$ & $50 \%$ of the quantity of waste generation as indicated in Extended Producer Responsibility Plan \\
$2022-2023$ & $60 \%$ of the quantity of waste generation as indicated in Extended Producer Responsibility Plan \\
2023 onwards & $70 \%$ of the quantity of waste generation as indicated in Extended Producer Responsibility Plan
\end{tabular}

MoEF\&CC 2018: 6

industries to possibly achieve. He concluded that unfortunately, recycling infrastructure and capacity were ignored in the E-waste Rules of 2016 which made the collection target issue further complicated.

Overall, the collection targets need to be realistic and attainable. This necessitates an understanding of the behavior of consumer citizens regarding their purchase and disposal of EEEs. Further, the demographic differences and socio-political-environmental variances should be acknowledged and worked out accordingly. Thus, as consumer behaviors differ from countries to countries and regions to regions, local specific studies are essential to establish the same. It is impossible to set up convincing collection targets and associated mechanisms without analyzing both individual and bulk consumers' behaviors in depth.

\section{Integration of the informal sector with the formal sector}

The United Nation's Global E-waste Monitor 2020 argued that informal sector is still largely involved in E-waste recycling in low- and middle-income countries (Forti et al. 2020). In developing countries and emerging economies such as India, South Africa, and China, informal sector has traditionally been playing a pivotal role in E-waste management. Economic value and inadequate legislation encourage an emerging recycling market of E-waste for instance, where rudimentary processing methods are widely used to extract valuable/precious metals with intense pollution creation (Soetrisno and Delgado-Saborit 2020). However, at the same time, one must acknowledge that such informal recycling activities have been contributing to a circular economy in these countries for years. Here lies the dilemma:

- Is integration of informal sector with the formal sector a viable option?

- Will such a collaboration lead to sustainable waste management practices?

So far, research activities exploring approaches towards recognizing the actors and flows in the informal sector for informed EPR-based policies have been few and far in between, especially with respect to integrating the informal sector with formal system of E-waste management (Davis 2020).

One of the experts (E01) observed that even after establishing the collection target of $70 \%$ from the year 2023 onwards, it is very likely that $30 \%$ of the E-waste will still be directed to the informal sector. He estimated that approximately 200,000 workers are currently engaged in various E-waste recycling activities in the informal sector in India. Accordingly, it will be unethical to deprive them of their livelihood options. He believes that rather than demolishing the informal sector, it is essential to empower the sector for better efficiency. While formalization has been encouraged 
by the policymakers, the contribution and role of the informal sector must also be acknowledged. For instance, the constructive potentials of the informal E-waste sector along with its relation to formal policies and actors have been given fewer attention, although the troubling facets of informal recycling are always extensively reviewed (Davis and Garb 2015). Another expert (E02) reiterates that informal sector needs to exist. However, he observed that there is no evolution in the sector, and it remains the same during the last several decades. For him, formalization of the informal sector is not required. Instead, informal sector should remain "informal." Converting it into a formal set up will reduce its efficiency. For instance, in the process of formalization, the excellent network of the informal sector with its doorto-door collection efforts will certainly suffer. Informal sector will lose its inherent characteristics in the formalization efforts. He further stated that formal sector is always bureaucratic in nature involving significant amount of paperwork, and thus, it creates barriers and hurdles.

Accordingly, instead of doing away with the informal sector, efforts should be directed towards a healthy collaboration between the informal and formal sector where best-of-thetwo-worlds could be used for sustainable E-waste governance in India. Ensuring sustainable and safe recycling activities along with improving the informal recyclers' source of livelihood is only achievable through mutual integration of informal sector with the formal sector and legalizing their important role in a country's E-waste management (Arya \& Kumar, 2020). Concentrating on the individual strengths of both informal and formal sectors, Davis and Garb (2015) suggested an "incremental ratcheting synergistic model" towards creating a valid alliance between the two sectors. The six key principles of the model are (Davis and Garb 2015):

- Understanding both the sectors

- Acknowledging integration as a constant and incremental process

- Engaging appropriate stakeholders and devising policies collectively

- Concentrating on curtailing major risks and supporting significant strengths of the informal E-waste sector

- Encouraging transformation by incentivizing rather than punishing the informal sector

- Integrating top-down and bottom-up management approaches

They argue that integrative interventions should concentrate on approaches for enabling innovative business models that support sustainable and clean routes without depending on government regulations or allowances (Davis and Garb 2015).

Overall, integration of both the sectors-informal and formal-needs considerable brainstorming by the policymakers, researchers, industries, civil societies, waste collectors/ scrap dealers, recyclers, and other relevant stakeholders. This is particularly true in a country like India which anyway has complex socio-economic, political, and environmental realities across the country. For instance, the urban and rural landscapes have different characteristics and waste management systems cannot remain untouched by them. However, at the outset, the stakeholders must consider whether such an integration is essential at all or if it is more smart to utilize best-of-the-two-worlds towards devising a sustainable waste management system.

\section{Conclusion}

Through expert interviews and policy document analysis, it has been observed that E-waste policy approaches in India are largely influenced by the EU's Waste Electrical and Electronic Equipment (WEEE) Directive which entered into force in 2003. While there were no "formal" policy transfer efforts from the EU, the Directive did act as the primary reference point while devising India's E-waste policy responses. The EPR is at the core of both the policies although its appropriateness in Indian scenario is still contestable and a topic of further debate and discussion. Thus, E-waste governance in India is a complex phenomenon. A wide array of socio-economic, cultural, political, and environmental factors together determines the success of any policy interventions in India and E-waste policies are no exception.

Absence of addressing the informal recycling sector emerges as one of the most prominent observations on both the E-waste (Management) Rules 2016 and E-waste (Management and Handling Rules) 2011. All the experts interviewed for this study recognized this concern as a significant lacuna in India's E-waste policy responses. India's recyclable waste management sector is dominated by the informal actors, providing ample employment opportunities to the urban poor, and diverting a huge volume of waste from landfills. Effectiveness of E-waste policies in India depends on how this sector is integrated in the policymaking processes. Since their inception, effectiveness of India's E-waste policies has been concerning albeit hardly addressed in the academic literature. An E-waste policy transfer effort from the Global North should align itself to the local circumstances of the Global South in order to garner success. The struggle for an operational E-waste policy in India provides testimony for it.

An important concern of India's E-waste policies is its scope. Although the EU's WEEE Directive considerably inspired India's E-waste policymaking initiatives, both Indian E-waste Rules of 2011 and 2016 are far from being as wideranging as compared to the WEEE Directive in terms of inclusion of the EEEs under its purview. Only 21 varieties of 
EEEs are included in the 2016's rules against a much broader inclusion of products in its European counterpart. Thus, there are further concerns regarding the comprehensiveness of the Indian E-waste policies and ambiguities of the proposed collection targets. Moreover, the uncertainties on the collection target is primarily a result of no credible being data available on the lifespan of EEEs in India. This requires urgent research attention for the success of Indian E-waste policy efforts.

Finally, there is this concern on integration of informal sector with the formal sector. I argue that both these sectors have some inherent strengths and weaknesses. There should be policy change for harnessing those strengths towards a healthy collaboration between the informal and formal sector where best-of-the-two-worlds could be used for sustainable E-waste governance in India. Consumers' E-waste disposal behavior and associated awareness determine the success of E-waste policy responses in any country. Accordingly, more research and policy attention should be diverted to understand the same. In a country as diverse as India, it is essential to acknowledge the demographic and socio-economic-political-environmental variances in order to devise effective E-waste policy solutions. One-size-fits-all policy approaches may not be successful in the country and thus, sustainable E-waste management in the country demands alternative policy responses.

Acknowledgements The author, Dr. Anwesha Borthakur, acknowledges the support provided by the European Union within the scope of the Marie Skłodowska Curie Individual Fellowship via Grant Agreement No. 844822.

Author contribution The sole author, Dr. Anwesha Borthakur, developed the idea of the paper, conducted the interviews, and was engaged in writing the paper.

Data availability The data will be protected as mentioned in the ethical approval application submitted to KU Leuven, Belgium. The personal data processing meets the requirements of the General Data Protection Regulation (GDPR) as approved by the KU Leuven's ethics approval committee.

\section{Declarations}

Ethics approval An ethical approval was taken from KU Leuven, Belgium, prior to conducting the study.

Consent to participate The interviews were accompanied compulsorily by an "Informed Consent Form." Only with the consent of the respondents interviews were conducted.

Consent for publication In the "Informed Consent Form," approval of the participants was taken for scientific publication of the data. The personal data processing meets the requirements of the General Data Protection Regulation (GDPR) as approved by the KU Leuven's ethics approval committee.

Conflict of interest The author declares no competing interests.

\section{References}

Ackah M (2017) Informal E-waste recycling in developing countries: review of metal(loid)s pollution, environmental impacts and transport pathways. Environ Sci Pollut Res 24(31):2409224101. https://doi.org/10.1007/s11356-017-0273-y

Amuzu D (2018) Environmental injustice of informal e-waste recycling in Agbogbloshie-Accra: urban political ecology perspective. Local Environ 23(6):603-618. https://doi.org/10.1080/ 13549839.2018.1456515

Asibey MO, Lykke AM, King RS (2020) Understanding the factors for increased informal electronic waste recycling in Kumasi. Ghana. Int J Environ Health Res 32(2):305-320. https://doi.org/ 10.1080/09603123.2020.1755016

Benson D, Jordan A (2011) What have we learned from policy transfer research? Dolowitz and Marsh revisited. Political Stud Rev 9:366-378

Borthakur A, Govind M (2017) Emerging trends in consumers' E-waste disposal behaviour and awareness: a worldwide overview with special focus on India. Resour Conserv Recycl 117:102-113. https://doi.org/10.1016/j.resconrec.2016.11.011

Borthakur A, Singh P (2020) The journey from products to waste: a pilot study on perception and discarding of electronic waste in contemporary urban India. Environ Sci Pollut Res. https://doi. org/10.1007/s11356-020-09030-6

Davis J-M (2020) A model to rapidly assess informal electronic waste systems. Waste Manag Res 39(1):101-107. https://doi. org/10.1177/0734242X20932225

Davis J-M, Garb Y (2015) A model for partnering with the informal e-waste industry: rationale, principles and a case study. Resour Conserv Recycl 105:73-83. https://doi.org/10.1016/j.resconrec. 2015.08.001

Dolowitz DP, Marsh D (2000) Learning from abroad: the role of policy transfer in contemporary policy-making. Governance $13: 5-23$

Doron A, Jeffrey R (2018) Waste of a nation garbage and growth in India. Harvard University Press

Evans M (2017) Introduction: is policy transfer rational policy-making? In M. Evans (Ed.), Policy transfer in global perspective (pp. 1-9). Taylor \& Francis. https://doi.org/10.4324/9781315246574-1

Forti V, Balde Cornelis P, Kuehr R, Bel G (2020) The Global E-waste Monitor 2020: quantities, flows and the circular economy potential, (Bonn, Geneva and Rotterdam: United Nations University/ United Nations Institute for Training and Research, International Telecommunication Union, and International Solid Waste Association

Harrell MC, Bradley MA (2009) Data Collection Methods: SemiStructured Interview and Focus Groups. RAND National Defense Research Institute, Santa Monica

Harriss-White B (2020) Waste, social order, and physical disorder in small-town India. J Dev Stud 56(2):239-258. https://doi.org/10. 1080/00220388.2019.1577386

Harriss-White B, Rodrigo G (2016) Discrimination in the waste economy: narratives from the waste workers of a small town. J Soc Incl Stud 2(2):3-27. https://doi.org/10.1177/2394481120160201

Knill C (2005) Introduction: cross-national policy convergence: concepts, approaches and explanatory factors. J Eur Publ Policy $12: 764-774$

MoEF\&CC (2016) Available at: http://greene.gov.in/wp-content/uploa ds/2018/01/EWM-Rules-2016-english-23.03.2016.pdf. Last accessed on February 24, 2021

MoEF\&CC (2018) Available at: http://greene.gov.in/wp-content/uploa ds/2019/09/2019091847.pdf. Last accessed on February 24, 2021 
Mukherjee I, Bali AS (2019) Policy effectiveness and capacity: two sides of the design coin. Policy Des Pract 2(2):103-114. https:// doi.org/10.1080/25741292.2019.1632616

Nagel SS (1986) Efficiency, effectiveness, and equity in public policy evaluation. Rev Policy Res 6(1):99-120. https://doi.org/10.1111/j. 1541-1338.1986.tb00651.x

Pereira A, de Miranda Ribeiro F, Jeffrey R, Doron A (2020) Waste policy reforms in developing countries: a comparative study of India and Brazil. Waste Manag Res 38(9):987-994. https://doi. org/10.1177/0734242X20938435
Zeng X, Mathews JA, Li J (2018) Urban mining of E-waste is becoming more cost-effective than virgin mining. Environ Sci Technol 52(8):4835-4841. https://doi.org/10.1021/acs.est.7b04909

Publisher's note Springer Nature remains neutral with regard to jurisdictional claims in published maps and institutional affiliations. 